\title{
The role of real humanism in the digitalization of schools: methodological aspects
}

\author{
Tatyana Eroshenko*, and Anastasia Melnik \\ Don State Technical University, 344000, Rostov-on-Don, Russia
}

\begin{abstract}
The introduction of digitalization in the educational space causes anambiguous reaction. Some consider it a tool for solving the problems accumulated in school, while others openly define it as a factor in the school dehumanization. In order to understand what digitalization brings to the schools, you need to know the goal of implementing it. The author believes that in the broadest sense school and society form a single whole. In connection with the rapid update of technologies in the production and non-production spheres, there is a need to add managerial relations in the labor sphere with pedagogical ones. Complicated out-ofschool conditions for younger generationeducation force the school itself to work more closely in synergy with society, and for this a democratic public schoolmust exist. A school that uses the "digitalization of the educational space" tool will have to implement the function of connecting with the past, determining its place in the present and future. Consequently, the school also performs the function of spiritual confrontation in hybrid wars. Skilful use of the "digitalization of the educational space" will create conditions in which the school can be useful for production and vice versa. The role of school in interaction with society is increasing due to the transformation of the cognition process into the main type of human activity. The tool of digitalization should be used in the environmental education and the entire society, since ecology currently includes all the pressing problems of humanity.
\end{abstract}

\section{Introduction}

Modern researchers of education K. Meteshkin, A. Morozova, O. Teplova, S. Kamenetsky, E. Voevoda, Saykili Abdula and others believe that one of the main functions of the school is to give a person knowledge or skills and socio-psychological qualities that would help him to live and realize himself in society. Of course, all these tools will quickly become obsolete in modern conditions, but their quality should be of such a kind that it could be easily updated [1-3]. From this understanding of the main function of the school, apparently, some of the national development goals of the Russian Federation until 2030 come: "the entry of the Russian Federation into the top ten countries in the world in terms of the quality of general education; formation of an effective system for identifying, supporting and developing the abilities and talents of children and young people, based on

* Corresponding author: russiaeroschenko-1970@mail.ru 
the principles of justice, universality and aimed at self-determination and professional orientation of all students: ensuring the presence of the Russian Federation among the top ten countries in the world in terms of research and development, including through the creation of an effective system of higher education; creation of conditions for the upbringing of a harmoniously developed and socially responsible personality based on moral and spiritual values of the peoples of the Russian Federation, the historical and cultural traditions...". It is written in the decree of the President of the Russian Federation of July 21, 2020 No. 474 "About the national purposes of development of the Russian Federation for the period till 2030". These goals are regretful to be setforsecondary, high school and academic science, which have just undergone not very successful series of reforms. There is plenty of material about the results of these reforms. The following Table 1 reveals the most general results of the education reforms in Russia.

Table 1. The most general results of the education reforms in Russia

\begin{tabular}{|c|c|c|}
\hline Results & Today & Before the Bologna System \\
\hline $\begin{array}{c}\text { The quality of the education } \\
\text { system in Russia as a whole }\end{array}$ & 3.5 & 7.7 \\
\hline $\begin{array}{c}\text { The quality of the university } \\
\text { applicant's training }\end{array}$ & 3.5 & 7.2 \\
\hline $\begin{array}{c}\text { The quality of the secondary } \\
\text { school graduate training }\end{array}$ & 3.3 & 7.2 \\
\hline
\end{tabular}

The table contains the data, taken from the article "Education Reform: the results are impressive" written by Nadezhda Khvylya-Olinter, an expert at the Center for Scientific Political Thought and Ideology, that conducted the expert survey to evaluate the results of the educational reform in Russia on a 10-point scale. 154 representatives of various scientific branches of universities (teachers, tutors, professors) compared the quality of the training of educational institutions graduates before and after Russia's entry to the Bologna system and the introduction of the Unified State Exam.

We will consider the reform of education as one of the types of reformatting of the educational space, and with it the entire pedagogical space. Over the past three decades, Russia has been involved in reform, or better to say, endless education reforms that lead to nowhere. Under the influence of the "brilliant" results of this reform: "... and without any ratings, under the pressure of everyday communication we are increasingly aware that we live in a society whose members do not understand neither what they are said nor what they say themselves..."as M. Delyagin notes in the article "Stupefying the Masses". Of course, these reforms will leave something positive: at least the awareness of the need to appreciate the experience of the past, the best of it. But in general, the fruits of the reform cause only negative feelings and sometimes angerof both practitioners and theorists of pedagogical activity. The dehumanizing role of the educational reforms, carried out in the country, is clearly noted by Professor V. Kutyrev in the article "Education or o-programming? (or how to achieve an advanced level of human degradation)". He emphasizes the following: "We are witnesses and participants of the initial stage of the end of education. Its zombification as an initial stage. The logic of the historical movement is as follows: up-bringing $\rightarrow$ education $\rightarrow$ knowledge management $\rightarrow$ consciousness management $\rightarrow$ programming. $=$ Personality $\rightarrow$ actor $\rightarrow$ zombie $\rightarrow$ cyborg $\rightarrow$ robot. This is the reality itself, it is happeningbeneath our very eyes, if we are not afraid of looking at reality as it is. If the process of bringing our education to the world level and preparing for its rebirth into programming is not able to be slowed down, it will only get worse. There will be no education in the twenty-first century. We need the ecology of education." 


\section{Materials and Methods}

\subsection{Two Types of Schools}

What kind of school is being created by the reforms in the educational space of modern Russia? In general, the existing history of education is presented to us by two real types of schools: a class school (not a unified, not a mass one) and a popular, democratic school (a unified, mass one). These are the two poles of the historical development of real and ideal types of school. There are various intermediate, hybrid forms between them. The first type of school is widely developed in the conditions of the following complex societies, slaveowning and feudal. In simple community societiesthere was a pedagogical and educational space, but there were no institutionalized schools. All the adults were teachers and all the children were students. The second type of school appears in the conditions of the origin and progressive development of bourgeois society. However, the connection of the school type to the historical time is not necessary. In regressive political and cultural periods in the history of a particular society one can observe the return of forms of archaic educational (pedagogical) space and, consequently, of earlier real and ideal types of schools. In the progressive ones, on the contrary, one can observe attempts to create a school of the future, a school that is ahead of its time.

\subsection{Class School}

A class school implies that a pupilbelongs to a certain class. This school prepares a person for the performance of class duties: a priest, a knight (warrior), a craftsman, a merchant, a servant. This school is authoritarian. Its main method is training. Pupils or their parents and even ordinary teachers are often deprived of participation in the management of school processing. Apparently, closed elite schools should also be consideredas a kind of class school. The experience of the Soviet school at some stages of its development can be called the experience of the school of the future, i.e., the school of real humanism. It is obvious that this type of school as a project has not been fully revealed, has not been implemented as well as the social project of "real humanism"as a whole. But the school that came before its time managed to do something. Its experience is not neglected in the West, in particular, in Finland and in the East - in China. In Soviet Russia the construction subjects of the educational space were obliged to adopt all the best from the experience of the functioning of the "old school" and rely "on a solid foundation of human knowledge" as V. Lenin noted in his work"On Up-bringing and Education".

\subsection{Probable Valuable Portrait of Modern Russian School}

So, which school are we developing: class or democratic, secular or religious? One can give the examples of the return to our pedagogical space of the class, religious and closed elite schools. Such a valuable and target confusion could have planned deliberately in advance.Butschool, parents, teachers and pupils only lost from such a wild diversity. According to the system of values, proclaimed by the Constitution of the Russian Federation, the modern Russian school should be, at least by definition, "democratic". The "democratic school" is also a valuable concept. And it should be noted that this term has disappeared, almost disappeared from our pedagogical literature [4-6]. 
1. A democratic (public) school is a school in which all participants of the pedagogical process from the administration to the teacher, students and parents, cooperate with each other, improve the educational process and manage the pedagogical process collectively.

2. The democratic school is open to all classes and social groups.

3. The democratic school prepares the individual to perform a variety of roles, to perform activities to the greatest extent appropriate to his abilities.

4. The democratic school does not perpetuate social inequality, but becomes itself an instrument for overcoming its most acute forms.

5. The educational objective of the democratic school is "man is a creator" and "man is a consumer", "homo economics"; they are only separate, important, but not the main, not leading features-roles.

The Soviet elements remaining in the Russian school stubbornly resist the imposed value criteria of the class school and strive to preserve the features of the democratic school. The reformers subordinated the reforms to their corporate interests and tried to distance the school from the rest of society: the opinions of the scientific, pedagogical and parent communities were not taken into account. The improvement of the education system, apparently, requires strengthening the relationship and interaction of the school and society.

Any type of society is itself a school in the broadest sense of the word. A person experiences the impact of not only natural, but also socio-anthropological factors, which determine his bi-planarity by their interaction. Natural factors include natural and climatic conditions, natural changes and catastrophes. Knowledge of these factors and knowledge about the possibility of its use (skills) is concentrated in everyday knowledge and understanding of nature and in scientific and theoretical natural science. After all, human existence realizes itself within nature.

By socio-anthropological factors we mean the factors that are relatively independent from purely natural ones, factors that have already appeared within society (school, science, army, government), but are producing a considerable effect on a person and society that is comparable to the natural and material ones. Let us recall Bismarck's recognition of the role of the teacher in the victories of Prussia. To an even greater extent, the increasing role of the teacher and, consequently, the school, is emphasized by Nikita NikolaevichMoiseev in the article "The Teacher system and the modern environmental situation". He believes that the teachers "influence not only on the fate of civilization, but also on the preservation of a man on the planet."

By socio-anthropological knowledgewe mean the entire human body knowledge about ourselves and our capabilities, which manifest themselves and are fixed in social psychology and ideology, mythology, historical memory, morality, religion, philosophy, human studies and in school curricula. Both types of knowledge (natural and socioanthropological) appear in a differentiated form, determined by the difference in the objects of knowledge, civilizations, national cultures and social classes, but they also show a tendency to integration. This process is confirmed by the development of interdisciplinary relations in both systems of knowledge and skills in accordance with the predictions of Karl Marx that later natural science should include the science about a man to the same extent that the science about man should include natural science and it will be one science.

\section{Results}

In a simple society the knowledge of the nature laws was incommensurable with the knowledge of the laws at the present time, but there were some spontaneous restrictions of pressure on nature, combining a pragmatic, ecological and moral aspects (not to kill pregnant females, restrict fishing during spawning, observe the rules for collecting 
mushrooms, berries, nuts, etc.). So, following these simple rules in a simple society it had a certain effect. Difficulties in overcoming excessive pressure on nature make the prospect of not only the "end of history", but also the end of the existence of a man as a phenomenon of the planet Earth. The shake-up of the human world by the coronavirus pandemic is another confirmation of this probability. Ignorance acquires a sinister influence on the economy and politics, threatening the preservation not only of individual societies, but also of human civilization as a whole [7-9]. In the modern conditions a high level of natural science and socio-humanitarian education of a person is not a luxury, but a condition for the survival of humanity, the level of education should strive to the maximum, so that each person feels not only as a consumer of knowledge, spiritual goods, but also a researcher and producer of spiritual goods, who shares them with all others. The products of spiritual creativity are initially and potentially not a commodity $[10,11]$. The increase in knowledge about nature enriches a person with new technologies that make his life easier, while self-knowledge puts forward more and more complex problems of a moral nature, so history is a constant progress in solving moral problems. The positive work of history is not so much in parting with the past or even more in a gross destruction of it, as in skilfully preserving a vital part of the past and including it in the present and future. The school is one of the structural divisions of the modern society, but at the same time it is a constructive reflection of the society: its main advantages and disadvantages. The connection between the school as a subsystem and the rest of society is that the society to a certain extent merges with its subsystem and itself acts as a "School" in the broadest sense. This is the dialectics of school-society relations.

Why does the concept of school in the broadest sense coincide with the whole society? First, like society, the school socializes a person (forms a person as a subject of the socioanthropological processes). Secondly, in the school the pedagogical relations of the subjects, being the leading ones, interact side by side with psychological, moral, legal and other types of social relations, and in society the real subjects of social relations are also either in the status of teachers, or in the status of students, or simultaneously in both statuses. Pedagogical relations permeate the entire society.

The society had the qualities of a school even when the school as an institution in society did not yet exist. In a simple (primitive society) social life and the process of education and upbringing merge into a single whole. We assume that a social life is essentially generated by synergy and resists the degradation and disintegration that aggressive natural and socio-cultural environments threaten it with. A true social life is always a social-anthropological life and a social-anthropological life is always a synergy of the individual-personal and collective, social. The school as a social institution can experience subjective changes: it can be improved, deteriorated, it can be destroyed as a social institution (subsystem), but the society as a material education (complex system) is a School objectively. Society appears together with the potential for the formation of a school in it as a social institution with the complication of society. The importance of the dialectical connection between school and society is currently increasing. Changes in society affect the school. The changes, experienced by the school, affect the society. The movement of society is much more complex than we imagine. It is, of course, carried out, but not in an infinitely straight line, but as a result of the inclusion of a reverse or a series of reverse movements in it. But the school cannot limit itself to providing individually the knowledge and skills of the generations of young men and women entering adulthood. It should also take on the function of participating in the stabilidization of society through the development and promotion of knowledge. The main weapon of the army is lethal. The main weapon of the school is knowledge. The school must cultivate knowledge and, therefore, the truth. The lack of knowledge, which is sometimes manifestedin militant ignorance, is fatal. 
The modern reality is the so-called "cognitive" wars: information-psychological, network, hybrid. The classification of the latest means of warfare has not yet been definitively established and will probably be updated and improved. But all of them are united by the possibility of achieving the strategic goals of the war, either with little use of lethal weapons, or without any practical use of such ones. The main goal of this kind of war, according to O. S. Gannova, is "to change the vector of public opinion, to prepare it morally for drastic changes, including a change in the leadership of the country through the destruction of the foundations of the state, not by destroying the military or economic potential of the country, but by a massive informational impact on the moral and psychological state of its population and leadership".Thus, those who lead these wars as a form of cognitive warfare, seek to achieve the usual goals of war without the use of lethal weapons. Force pressure replaces "moral" pressure. The moral factor has always been taken into account in military theory and the art of war, but today it is put forward in the first place. Its essence is to increase or maintain the morale of the population of your country and lower the population of the enemy country. It implies lowering the level of moral culture, moral qualities, manipulating public consciousness, disinformation of the population, inciting suspicion and distrust, plunging the country into artificial "man-made" chaos. One of the main technical means of conducting such wars is the latest, constantly improving media.

But the weapon properties are not the technical means of information delivery themselves, but the content of the transmitted information. The wars, that we have conventionally called "cognitive wars", are wars in which the weapons are not natural, but socio-anthropological factors. Among them, as already noted, is the school. The sense of self-preservation pushes humanity to limit the use of lethal weapons and expand the use of cognitive means of influence on the opposing side. The First World War can only be considered over when lethal weapons are completely replaced by cognitive weapons. And at present, before cognitive means there is a likely prospect of a complete replacement of battles with the use of lethal weapons with rivalry in the spiritual sphere, spiritual rivalry, moral superiority. Of course, the content of information, i.e., the power of cognitive warfare weapons, can be either immoral, degrading or moral, uplifting. Spiritual superiority goes to the one who is constantly in the knowledge of himself. But it is the emerging opportunityto bring the First World War finally to the end, that opens a new era in the history of mankind. Humanity can organically enter into the nature of the planet Earth, which will finally become its common home in the face of the boundless Cosmos, after which we all together need look. Digitalization as the basis of the new technological rise,that is taking over the school, should also aim at strengthening it as a weapon of spiritual confrontation in cognitive wars, which is incompatible with attempts to dehumanize it.

\section{Discussion}

\subsection{The School as a Spiritual Institution}

The school as a spiritual institution appears in a complex society almost simultaneously with the institute of religion and often at the temples. The process of the origin of the school reflects the separation of spiritual activity from labor. It was intended mainly for the representatives of the ruling classes, who had the privilege of engaging in intellectual labor. For the working classes the production process itself wasas a school.

Today we observe a simultaneous increase in the problem of bringing schools closer to production and an increase in the importance of schools as a spiritual factor in the education and formation of a person. What is the basis of the spirituality of the modern school? 
Knowledge. Of course, knowledge. But knowledge is not only scientific. Science (especially natural science) has not only raised people materially above all living beings on the planet (except, perhaps, viruses and microbes), but also created technical opportunities for the self-destruction of humanity in the absence of clear scientific knowledge and spiritual and moral factors in human civilization that guarantee against this danger. Knowledge of nature, naturally, is always incomplete and will not save people without knowledge of their own human nature from self-destruction. Scientific knowledge about man is incomplete. Therefore, human practice identifies non-scientific forms of knowledge and knowledge that are included in the concepts of spirituality and culture: mythologicalreligious and philosophical knowledge, art and morality. And the content of these best examples of national and world cultures should be included organically in the school program. We believe, that in the end the data of non-scientific forms of knowledge have both empirical and rational bases. However, both experience and reflection are carried out here in a slightly different way than in scientific knowledge. They correspond more in some aspects to the knowledge of the human world and the perception of them by a person, and not by a machine. But digitalization can play an auxiliary but important role in getting to know the content of the best samples of world and national cultures.

Digitalization, if this means a new level of technological development, is not intended to reduce the number of teachers, but to reduce the number of students in the classroom by increasing the number of teachers who are well prepared for this difficult work. The spirituality of the modern school should be built on the basis of its connection with modern production, with modern science and with all the accumulated wealth of spiritual culture.

\subsection{The Modern School}

In Russia, for the most part the modern school is separated from real work. This is in the manufacturing areas due to the digitalization, where the number of working robots should decrease and the number of robots replacing them should increase.In the most important areas for human development and improvement, i.e., in education, science, and healthcare, the number and quality of employees should increase. Educational and labor, participation of students within their powers in the production and non-production areas of work is vital.

It is necessary to return the polytechnic qualities of the Russian school, which were most clearly defined in the pedagogical experiments of A. S. Makarenko. His commune gradually switched to self-financing and not only paid for the work of teachers, the maintenance of pupils, summer trips, visits to theaters, etc., but also gave profit to the state. Of course, it is impossible to repeat the experience of A. S. Makarenko nationally, but it is possible to create the conditions in which the school would be useful to various spheres of labor activity, and the sphere of labor activity is possible for the school. The school should be connected with the production and non-production spheres of labor activity. The moral and pedagogical meaning of this connection is very important.

\subsection{School and Science}

The institute of science is one of the most recent. It may not have reached its full functional maturity yet. Objectively the process of cognition (scientific and non-scientific as well) is so complex and diverse and significant for the modern society that it requires turning it into the main type of human activity. In the main types of human activity the importance of the scientific and search component increases. The importance of working with accumulated knowledge increases. There is a problem of scientific study of the process of synergy of scientific and non-scientific knowledge of the world. Both secondary and higher schools are acutely aware of the need to "compress" knowledge, but without losing its content. Ideally, 
each school is a laboratory of pedagogical science. And depending on their real conditions, schools can engage in scientific research in various fields in cooperation with universities [12-14].

\subsection{School and Ecology}

Man escaped from the animal state, stood in some respect above nature, but he never learnt to live in harmony with nature. Today, environmental problems absorb all the most pressing problems of human existence into a single node. This node defines, in our opinion, three most important areas: the ecology of science, the ecology of production and the ecology of man. The school is relevant to all three, but especially to human ecology. The latter can be divided into the ecology of the physical state of a person and the social ecology. The ecology of the physical condition is the field of health care, but in close cooperation with both the school and parents. Parents in Moscow, who have applied to the higher authorities, are concerned about the uncertainty of the impact of the DEE ("Digital Educational Environment") on the health of students. The parent community does not understand how the introduction of a digital educational environment can be carried out without conducting long-term prolonged scientific research on the impact of DEE on students.

Under social ecologywe understand the system of training and teaching people the skills of synergistic interaction with nature and other people and societies. The implementation of the problems of social ecology covers the entire set of school functions, but the attractor around which it seems most natural to organize the formulation and solution of these supercomplex problems is ethical problems. Why? We return to the original meaning of the word ethos: shared housing and rules, norms generated by a shared hostel, uniting the residents in it, aimed at overcoming individualism and aggressiveness. We also rethink the concept of "dwelling". The dwelling here denotes the set, which includes all the dwellings that people have ever used (starting with caves) and the territories where people live (starting with the territory of the ancestral community and up to the common territory that the planet Earth provides for people to live together). Ethics, having its own cognitive system, performs one of the functions that make up the essence of human existence: the generation and processing of moral and moral information necessary for the self-preservation and development/improvement of society and the person in it, the person and the society whose ethos would correspond to the person. The main enemies of the real humanism are: ignorance and moral underdevelopment, i.e., lack of spirituality, supported by the world of private-property relations and widely cultivated media, which are in the hands of the same private-property world [15-17]. The modern school, including the higher school, today faces a difficult choice - to find the optimal ways of its development. The assessment of the ongoing changes is ambiguous, no matter how contradictory the assessments may be, the society, first of all, the teachers themselves are interested in building up the spiritual potential of the educational space. All components of the school: the program, the curriculum, the teaching teams, the teacher's activities in the classroom and after-school time, the walls in the classrooms and corridors should educate the person, prepare him for creative synergistic interaction with other people. The school should realize itself in close connection with the real life of the Russian society.

\section{Conclusions}

1. The improvement of the school and the entire education system is probably in the direction of strengthening the relationship and interaction of the school and society.

2. The positive work of history is not so much in parting with the past or even more in a gross destruction of it, as in skilfully preserving a vital part of the past and inserting it 
into the present and future. The school can use digitalization technologies to preserve and determine the place of the past in the present and future.

3. Digitalization should also aim at strengthening the school as a weapon of spiritual confrontation in cognitive wars, which is incompatible with attempts to dehumanize it.

4. Digitalization is not to reduce the number of teachers, but to reduce the number of students in the classroom by increasing the number of teachers who are well-prepared for this difficult work.

5. Ideally, each school is a laboratory of pedagogical science. Schools, depending on their actual conditions, can engage in scientific research in cooperation with universities.

6. The school should realize itself in close connection with the real life of the Russian society.

\section{References}

1. K. Meteshkin, A. Sokolov, O. Morozova, N. Teplova, Journal of Education, Health and Sports 6 (7), 375-390 (2016). doi: 10.5281 / zenodo.58067

2. SYu. Kamenetskiy, RUDN journal of informatization of education 16 (1), 64-72 (2019). doi: 10.22363/2312-8631-2019-16-1-64-72

3. E.V. Voevoda, Professional Discourse and Communication 2 (2), 89-94 (2020). doi: 10.24833/2687-0126-2020-2-2-89-94

4. D. Baczała, Przegląd Badań Edukacyjnych 1 (26), 7 (2018). doi: 10.12775 / PBE.2018.001

5. S. Abdula, Journal of Educational Technology and Online Learning (2019). doi: 10.31681 / jetol. 516971

6. M. Ferrari, Development relations between mind, brain and education (2010). doi: 10.1007 / 978-90-481-3666-7_14

7. G. Gobo, European Journal of Cultural and Political Sociology 3 (2-3), 1-5 (2016)doi: 10.1080 / 23254823.2016.1209886

8. V.N. Rudometov, Glocalization: A Critical Introduction (Routledge, London, 2016). doi: 10.4324 / 9781315858296

9. U.I. Robinson, International Sociology 26 (6), 723-745 (2011). doi: 10.1177 / 0268580910393372

10. L.V. Maksimov, Philosophy and Culture 11, 1498-1505 (2016). doi: 10.7256 / 19992793.2016.11.21062.

11. A.A. Borisenkov, European Journal of Humanities and Social Sciences 2, 43-52 (2013). doi: 10.7256/1339-3057.2013.2.10283.

12. A. Person, Framing Social Interaction. Continuities and Cracks in Hoffmann Frame Analysis (2018). doi: 10.4324 / 9781315582931

13. G. McKenzie, Interpreting Charles Taylor's Social Theory of Religion and Secularization 133-167 (2017). doi: 10.1007 / 978-3-319-47700-8_6

14. A. Portes, M. Zhou, Annals of the American Academy of Political and Social Sciences 530 (1), (2010). doi: 10.1177 / 000271629353000106

15. F. Cano, Psychology, Medicine The British journal of educational psychology (2005). doi:10.1348/000709904X22683

16. N.G. Osipova, Vestnik MGU, Series 18 Sociology and Political Science 25 (4), 124 153 (2020)doi: 10.24290 / 1029-3736-2019-25-4-124-153

17. J. Stepniski, The Wiley Blackwell Companion to Sociology, 21-38, (2019). doi: 10.1002 / 9781119429333.ch2 